\title{
Síndrome de Apert: tratamiento ortopédico
}

\author{
Apert Syndrome: orthopedic treatment
}

\author{
Daniel López López ${ }^{(1)}$, Francisco Alonso Tajes ${ }^{(1)}$, \\ Carolina Rosende Bautista ${ }^{(1)}$ y Luis López López ${ }^{(1)}$ \\ (1) Profesor de Podología de la E.U de Enfermaría e Podoloxía. \\ Departamento de Ciencias da Saúde. \\ Universidade da Coruña.
}

\author{
Correspondencia: \\ Prof. Daniel López López \\ Departamento de Ciencias da Saúde da \\ E.U Enfermería e Podoloxía \\ Universidade da Coruña \\ C/ Naturalista Seoane, Esquina San Ramón S/N \\ 15403 Ferrol \\ A Coruña
}

Fecha de recepción: 3 septiembre 2009

Fecha de aceptación: 2 diciembre 2009

Los autores declaran no tener ningún tipo de interés económico o comercial.

\section{RESUMEN}

El Síndrome de Apert es un trastorno autosómico dominante, caracterizado por craneosinostosis, hipoplasia del tercio medio de la cara y sindactilia de manos y pies.

Presentamos un caso de una mujer caucásica, de 45 años de edad, diagnosticada a las 24 semanas de gestación, de Síndrome de Apert de Tipo I, después de realizar ecosonograma en el cual se observaron las alteraciones características de este síndrome.

La paciente refiere dolor a nivel de la primera cabeza del primer metatarsiano del pie izquierdo, de larga evolución que mejora con el reposo y con la ingesta de analgésicos orales, por lo que se procede a la realización de tratamiento ortopédico que palie el proceso patológico.

Palabras clave: Acrocefalosindactilia Tipo I, Craneosinostosis, Sindactilia, Apert Síndrome.

\begin{abstract}
Apert syndrome is an autosomal dominant disorder characterized by craniosynostosis, midfacial malformations and symmetric syndactyly of hands and feet.

We present a case of a female Caucasian, 45 years old, prenatal diagnosis at 24 weeks gestation, apert syndrome type I, after sonography showing features deformity were observed characteristics.

She refered pain at the first head of the first metatarsal of the left foot, long evolution that improves with rest and with the intake of oral analgesics, which is the realization of orthopedic treatment palie that the disease process.
\end{abstract}

Keywords: Acrocephalosyndactyly Type I, Craniosynostosis. Syndactyly, Apert Syndrome.

Sumario: 1. Introducción. 2. Definición. 3. Fisiopatología. 4. Etiología. 5. Clínica. 6. Diagnóstico. 7. Diagnóstico diferencial. 8. Caso clínico. 9. Tratamiento ortopédico. 10. Conclusiones. 11. Bibliografía.

\section{Referencia normalizada:}

López López D, Alonso Tajes F, Rosende Bautista C, López López, L. Síndrome de Apert: tratamiento ortopédico. Revista Internacional de Ciencias Podológicas 2011; 5 (1): 29-35. 


\section{INTRODUCCIÓN}

El Síndrome de Apert, forma parte de los casi 6.000 síndromes genéticos conocidos. Esta enfermedad genética, puede ser hereditaria o presentarse sin que existan antecedentes familiares conocidos.

Se trasmite como rasgo autosómico dominante, aunque la mayoría de los casos se deben a mutaciones de novo ${ }^{(1)}$.

Las primeras menciones sobre este síndrome, fueron realizadas en el año 1842 por Baumgartner. Sin embargo, fue el médico francés Eugène Charles Apert, quien después de cursar los estudios de medicina y especializarse en pediatría en París, se interesaría en la investigación de malformaciones congénitas y enfermedades genéticas, siendo el primero en describir y publicar en detalle este síndrome, en el año 1906, razón por la cual lleva su nombre ${ }^{(2)}$.

\section{DEFINICIÓN}

El síndrome de Apert es un desorden genético incluido dentro del amplio grupo de las anomalías craneofaciales, caracterizado por craneosinostosis, hipoplasia del tercio medio de la cara, sindactilia simétrica de manos y pies y retardo mental de grado variable ${ }^{(3)}$.

\section{FISIOPATOLOGÍA}

Durante el proceso de formación de los gametos (células sexuales portadoras de la información genética de los padres), se han identificado mutaciones en un gen en el cromosoma numero 10 , que se conoce con el nombre de "Factor Receptor 2 del Crecimiento Fibroblástico", en el gen se produce de manera errónea sustituciones de citosina por guanina produciendo un cambio del aminoácido serina por triptófano (s252w; c934g) o de prolina por arginina (s252w; c934g) ${ }^{(4)}$. Estas dos mutaciones son responsables del $99.2 \%$ de los casos del síndrome de Apert. Las dos mutaciones involucran cambios en aminoácidos adyacentes a la región de unión del receptor.

Este cambio va a provocar al igual que las mutaciones descritas en el gen del FGFR2 una mayor avidez por las proteínas que lo estimulan. Produciendo así las señales moleculares responsables de cierre prematuro de las suturas craneales, mecanismo también relacionado con la presencia de sindactilia y también va a estar asociado al desarrollo de la cámara anterior del ojo y la mutación de Ser351Cys, que también se relaciona con la craneosinostosis y alteraciones oculares además, de un fenotipo más severo y un peor pronóstico como en el síndrome Pfeiffer tipo 2 y 3.24 que se ha asociado a la mutación s252w la edad paterna avanzada $^{(5)}$.

\section{ETIOLOGÍA}

El síndrome de Apert es el resultado de una mutación genética que se puede heredar de un padre que sufre del mismo síndrome o se puede tratar de una mutación nueva. Ocurre aproximadamente en 1 de cada 160.000 nacimientos vivos, y existe 1 de 2 posibilidades $(50 \%)$ de que se pase esta condición a su hijo. Esto se debe a que cada uno de nosotros obtiene la mitad de nuestra composición genética de cada padre.

Sin embargo, el Síndrome de Apert no es un rasgo recesivo, lo que significa que un hijo normal de un padre con el Síndrome de Apert no es más probable que tenga un hijo con este síndrome que cualquier otra persona sin esta condición. Del mismo modo, si el padre tiene un hijo con el Síndrome de Apert y no tiene el síndrome no va a ser más propenso a tener otro hijo con el Síndrome de Apert que cualquier otra persona en la población. Los estudios han demostrado que el Síndrome de Apert ocurre con más frecuencia en los padres que son mayores de edad ${ }^{(6,7)}$.

La literatura también lo relaciona con mutaciones en otros genes como el P253R relacionado con la sindactilia y el S252W con el paladar hendido ${ }^{(8)}$.

Se ha calculado una prevalencia de 15 casos por cada millón de nacimientos y representa el $4,5 \%$ de todos los casos de craneosinostosis, con una distribución por sexo de 1:1, aunque en la población asiática se considera que alcanza la cifra de 22,3 por cada millón ${ }^{(9)}$. Estudios publicados por Cohen y col en 1992 hacen una evaluación comparativa de la prevalencia de nacimientos con síndrome de Apert entre, Dinamarca, Italia, España y cuatro áreas 
de los Estados Unidos, dando como resultado 15.5 afectados por un millón, esta cifra duplica la relación de publicaciones anteriores ${ }^{(10)}$.

\section{CLÍNICA}

Se caracteriza por malformaciones en cráneo, cara, manos y pies, además de diversas alteraciones funcionales, que varían mucho de cada paciente, las características más significativas son:

1. Cráneo: se produce una craneosinostosis (cierre prematuro de los huesos del cráneo), provocando la deformidad del cráneo y la falta de espacio para la expansión del cerebro y acrocefalia (aspecto largo y puntiagudo de la cabeza) y aplanamiento de la frente y del occipucio ${ }^{(11)}$.

2. Cara: se aprecian, rasgos faciales inusuales por el cierre prematuro de las suturas faciales tales como: hipertelorismo (aumento de la separación de los ojos), hipoplasia (desarrollo incompleto o defectuoso) del tercio medio facial, exoftalmos (protusión anormal del globo del ojo), macroglosia (lengua anormalmente grande), maloclusión dental (dificultades en el cierre de la arcada superior e inferior), paladar ojival (paladar en forma de bóveda), fisura palatina (cierre incompleto de la bóveda de la boca) ${ }^{(12)}$.

3. Maxilares: Maxilar superior con paladar ojival, pudiendo presentar fisura palatina o úvula bífida, arco maxilar en forma de $\mathrm{V}$ con múltiples apiñamientos dentales, hiperplasia gingival generalizada, la mandíbula aparece en relación Clase III con respecto al maxilar superior. También se han observado alteraciones en el patrón de erupción de los dientes ${ }^{(13)}$.

4. Extremidades: a nivel de las manos y los pies aparece la sindactilia, rango distintivo que la difiere de otros síndromes, con fusión generalmente de los dedos índice, medio y anular, y segundo, tercero y cuarto dígito respectivamente. Puede existir la presencia de una sola uña grande entre los dedos fusionados lo cual da el aspecto característico de "cuchara de sopa". La unión puede estar confinada solamente a los tejidos blandos o por el contrario in- volucrar también al hueso en cuyo caso se presenta una fusión parcial o total de los dedos pudiéndose clasificar en ${ }^{(14)}$ :

- Sindactilia Tipo I: fusión del $2^{\circ}$ al $4^{\circ}$ dedo del pie, quedando libres el $1^{\circ}$ y el $5^{\circ}$ dedo de los pies, es la más común.

- Sindactilia Tipo II: el primer dedo queda aislado mientras que los dedos menores aparecen fusionados.

- Sindactilia Tipo III: la menos común, se caracteriza por la fusión de todos los dedos

Las extremidades superiores se encuentran acortadas con aplasia o anquilosis de algunas articulaciones, especialmente la de los hombros, codos y cadera.

5. Aspecto Neurológico: Puede existir una inteligencia normal o presentar varios grados de retardo mental siendo el más común el retardo moderado. También podemos encontrar en algunos casos hidrocefalia con la consecuente alteración de la presión intracraneal.

6. Piel: Se presenta hiperhidrosis generalizada y acné severo.

7. Sistémico: se puede caracterizar por una gran cantidad de afecciones que no son comunes a todos los individuos que padecen de esta enfermedad, pero se encuentran presentes en algunos de ellos, a continuación se mencionan algunas de estas afecciones: Defectos Cardiovasculares, Atresia Pulmonar, Ducto Arterial Permanente, Fístula Traqueoesofageal, Estenosis Pilórica, Riñones Poliquísticos, Infecciones Otológicas y Apnea del Sueño ${ }^{(15,16)}$.

\section{DIAGNÓSTICO}

El uso de ultrasonidos a partir de las 20 semanas de gestación va a permitir la observación y sospecha de alteraciones anatómicas en el feto, para ello se sigue el trayecto de suturas y fontanelas, en este síndrome, la translucencia habitual que se observa entre los huesos del cráneo no existe ${ }^{(17)}$.

Estas malformaciones pueden confirmarse con la realización de ecografía tridimensional, resonancia magnética nuclear ${ }^{(18)}$ y la realiza- 
ción de una prueba genética que demuestre la mutación en el gen FGFR2.

Al nacer, el diagnóstico se establece por la clínica y hallazgos radiológicos en cráneo, manos, pies. La realización de fondo de ojo es extremadamente útil como confirmatorio de los cambios esperados a este nivel ${ }^{(7)}$.

\section{DIAGNÓSTICO DIFERENCIAL}

El diagnóstico diferencial hay que establecerlo con otras enfermedades que cursan con asimetría craneal y facial como los síndromes de Crouzon, Fraccaro y con el síndrome 18 q heredado y otros con craneosinostosis como los de Carpenter, de Saethre-Chotzen y de Pfeiffer. Las características clínicas de estos síndromes y el que nos ocupa permiten hacer claramente la diferenciación ${ }^{(1)}$.

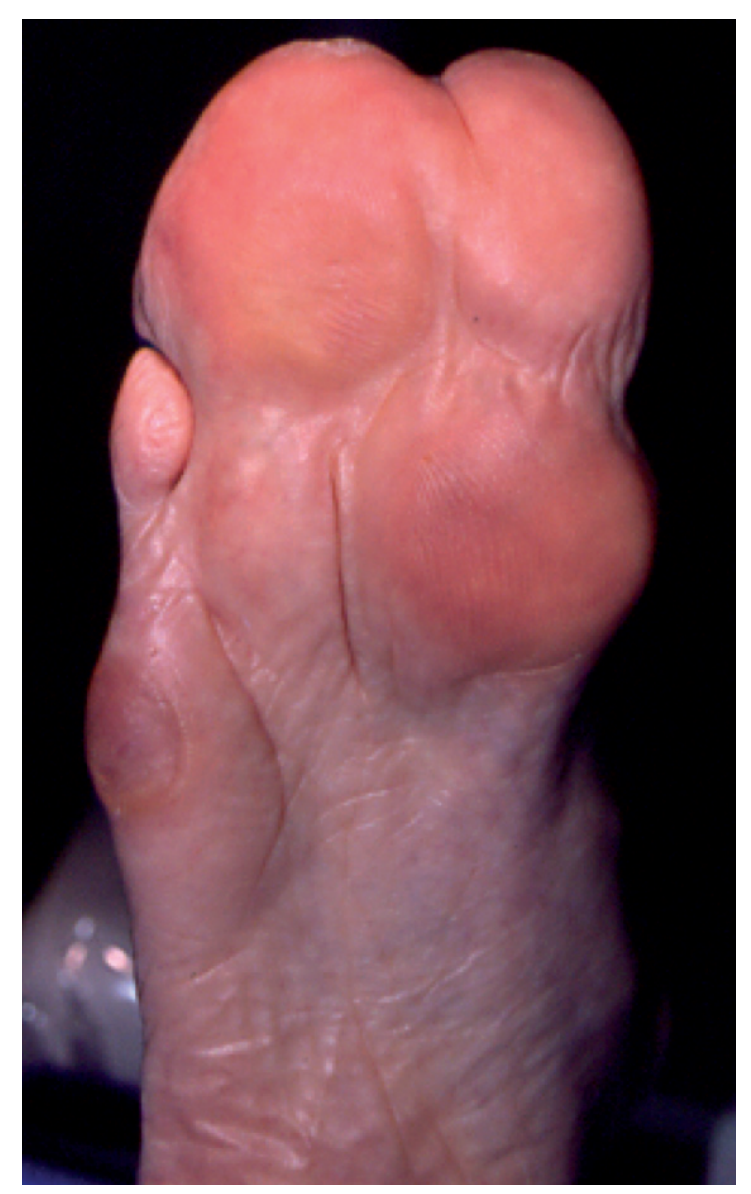

Figura 1. Aspecto plantar del pie patológico.

\section{CASO CLÍNICO}

Mujer caucásica, de 45 años de edad, diagnosticada en el momento del nacimiento de Síndrome de Apert de Tipo I y que acude a consulta por presentar sesamoiditis.

La paciente refiere dolor a nivel de la primera cabeza del primer metatarsiano del pie izquierdo, de larga evolución que mejora con el reposo y con la ingesta de analgésicos orales (Figura 1).

El pie patológico, pie izquierdo, se encuentra caliente y edematizado con respecto al pie derecho que se encuentra asintomático (Figura 2).

A la exploración física en descarga de ambos pies, la paciente presenta:

1. Arco longitudinal interno elevado.

2. Queratosis de grado medio en $1^{\mathrm{a}}$ y $5^{\mathrm{a}}$ cabeza metatarsal.

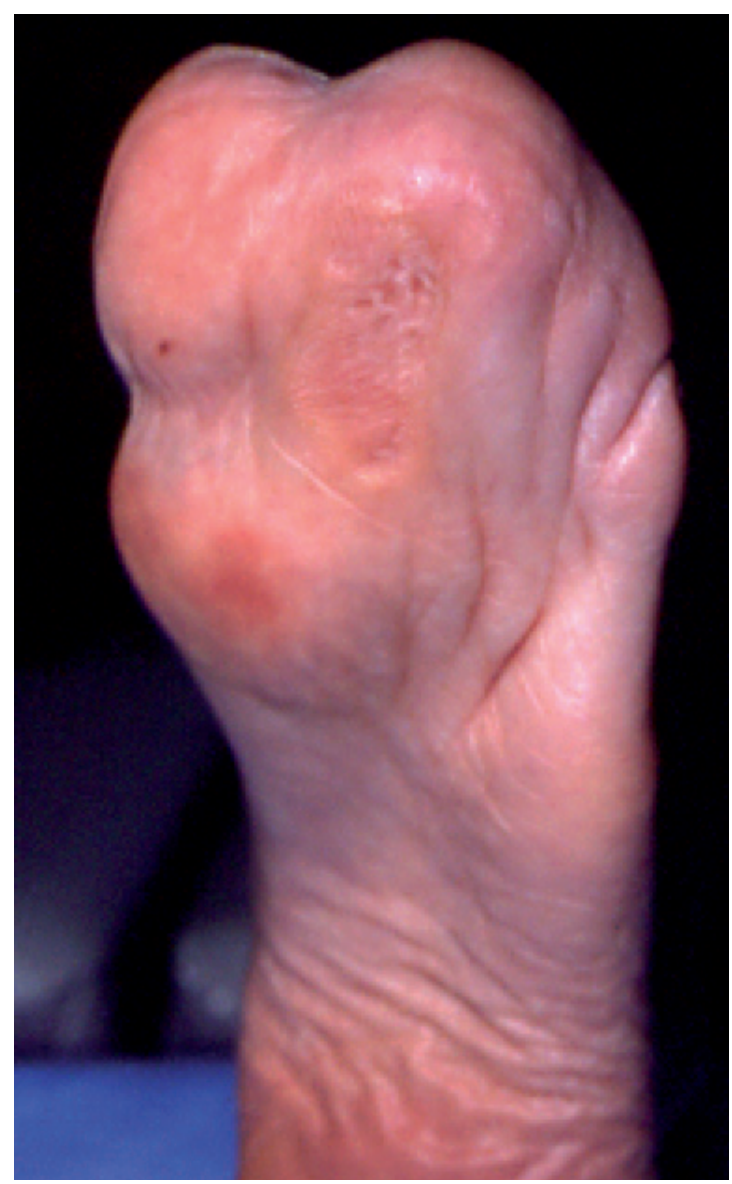

Figura 2. Aspecto plantar del pie asintomático. 
3. Movilidad abolida en los metatarsianos centrales y movilidad limitada en $1^{\circ}$ y $5^{\circ}$ metatarsiano (Figura 3).

Del mismo modo al valorar a la paciente en bipedestación estática, en el plano frontal sobre el podoscopio, se puede observar una deformidad de antepie valgo con flexión plantar del primer metatarsiano, como consecuencia de:

1. Arco longitudinal interno menos elevado en carga que en descarga.

2. Aumento de presiones a nivel del talón provocado por la inversión de la articulación subastragalina que contribuye a un incremento de carga, a nivel del primer metatarsiano de ambos pies.

Para finalizar el examen físico realizamos un análisis de la marcha, con la ayuda de una

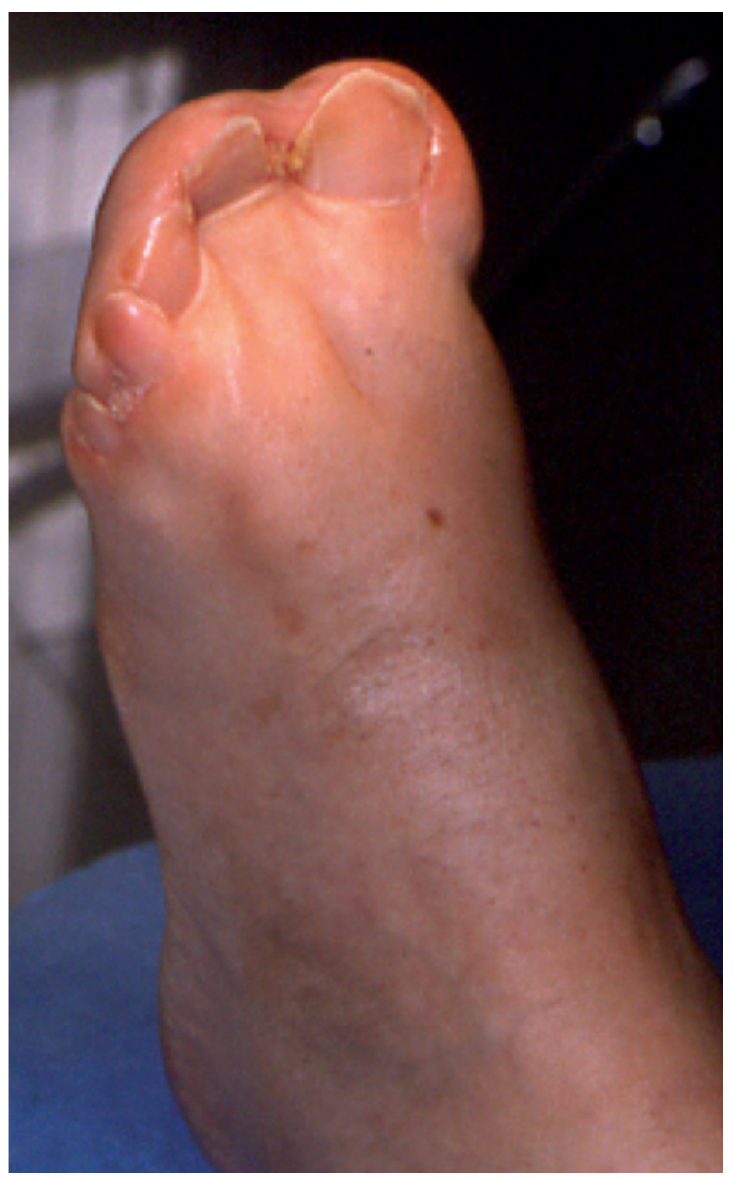

Figura 3. Visión dorsal en descarga del pie izquierdo plataforma de presiones, gracias a la cual se puede apreciar que durante la fase de contacto existe una limitación de movilidad de la articulación mediotarsiana que obliga a dorsiflexionar el primer radio para invertir la articulación subastragalina que conduce a una sobrecarga de la cabeza del primer metatarsiano.

En la fase de propulsión, se detecta una sobrecarga del $5^{\circ}$ metatarsiano con un hiperqueratosis difusa, como consecuencia de la movilidad subtalar y mediotarsiana que es necesaria para llevar el retropié a una posición vertical para poder inhibir la capacidad de plantarflexión del primer radio.

En el estudio radiológico se puede observar en ambos pies:

- Sinostosis entre la $3^{a}$ cuña y tercer metatarsiano.

- Fusiones parciales entre el primer y $2^{\circ}$ metatarsiano.

- Sinfalangia en todos los dedos (ausencia de falanges distales).

\section{TRATAMIENTO ORTOPÉDICO}

El tratamiento ortopédico tendrá como finalidad mantener el antepie en una posición de ligera eversión con respecto al plano frontal (19), así mismo pretendemos obtener una posición funcional y neutra de la articulación subastragalina, para ello realizamos un molde de escayola en carga, buscando obtener una estabilización la articulación calcáneocuboidea cuando esté bloqueada (cabeza del astrágalo se mantenga detrás del escafoides) ${ }^{(20)}$.

A continuación, se obtiene el positivo, y se realizan los cambios adecuados para permitir el desplazamiento de los tejidos blandos en carga y el descenso necesario del ALI para absorción de las cargas.

Se realiza ortesis plantar confeccionada en resina con una cuña pronadora de antepie ${ }^{(21)}$, buscando como finalidad dejar la bisectriz del antepié en posición vertical y a nivel de retropie colocamos una talonera neutra para intentar estabilizar la articulación de tobillo.

Para finalizar y sustituir los segmentos digitales ausentes y rellenar la puntera del calzado se procede a incluir una prótesis de antepié, insertada en el mismo soporte plantar ${ }^{(22)}$ (Figura 4). 


\section{CONCLUSIONES}

El síndrome de Apert es una patología que forma parte del grupo de las craneosinostosis, por lo tanto, entre los diagnósticos diferenciales se deben considerar otros síndromes como el de Cruzon, Chotzen, Pfeiffer, Noack, Carpenter y Goodman.

La detección temprana es vital debido a que la rápida instauración de un tratamiento idóneo por parte de los diferentes especialistas debe comenzar desde el momento del nacimiento. Es por ello, la necesidad de conocer los diferentes rasgos que se han descrito en el aspecto sistémico de esta patología para correlacionar los signos y síntomas que se puedan presentar a lo largo del desarrollo del individuo afectado.

Aunque la incidencia de aparición es en edades tempranas no es elevada debido a que se trata de un trastorno del desarrollo, es interesante observar como el primer caso fue diagnosticado en edad adulta ya que este tipo de pacientes con tantas alteraciones es remitido constantemente a muchos clínicos, por desconocimiento de la enfermedad.

El podólogo general y a su vez los especialistas en ortopodología y cirugía podológica juegan un papel muy importante en lo que se refiere al manejo de todas las patologías en los pies que presentan estos pacientes.

Es importante entender el concepto de manejo multidisciplinar de los pacientes y en especial con síndrome de Apert, ya que a través de un manejo integral de estos enfermos se pueden obtener unos resultados excelentes desde el punto de vista funcional, estético y psicosocial, que repercutirá en la mejoría de su calidad de vida.

Así mismo, la adecuación de tratamientos ortopédicos en pacientes con malformaciones congénitas en los pies y los posteriores controles biomecánicos, para valorar el tratamiento ortopédico que presenta, va a permitir una mejora significativa en su deambulación y en su propia autonomía.

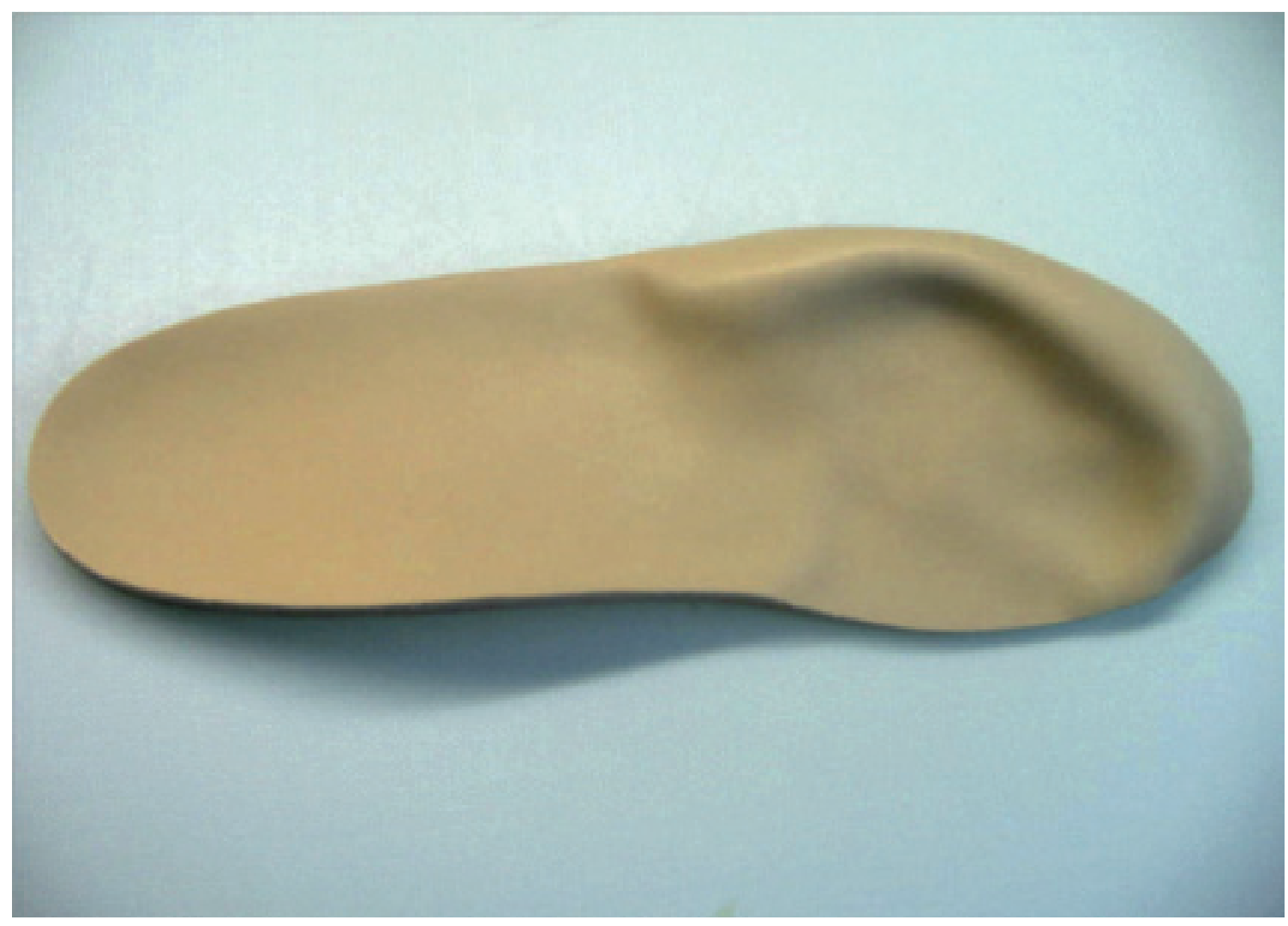

Figura 4. Visión dorsal de la ortesis confeccionada del pie afecto. 


\section{BIBLIOGRAFÍA}

1. Fanaroff-Martin, Enfermedades del feto y el recién nacido, 1992; 743, 1368.

2. Jones K. L. Smith's Recognizable patters of human malformations. 5th Ed. Philadelphia: WB Saunders Company; 1997.

3. Katzen JT, Mc Carthy JG. Syndromic and other congenital anomalies of the head and neck. Otolaryngol Clin North Am 2000;33:1257-1284.

4. Cuttone JM, Brazis PT, Miller MT, Folk ER. Absence of the superior rectus muscle in Apert syndrome. J Pediatr Ophthalmol Strabismus 1979; 16: 349-54

5. Wilkie AO, Slaney SF, Oldridge M, Poole MD, Ashworth GJ, Hockley AD, et al. Apert syndrome results from localized mutations of FGFR2 and is allelic with Crouzon syndrome. Nat Genet 1995; 9:165-72.

6. A guide to understanding the syndrome of Apert. Children's craniofacial association. Dallas, TX: 2008.

7. Wilkie AOM. Craniosynostosis: genes and mechanism. Hum Mol Genet 1997;6:1647-1656.

8. Carro E, Fernández L. S. Síndrome de Apert. Presentación de un caso. Rev Cubana Pediatr 2005; $77(3-4)$

9. Tolarova, MM: Harris JA, Ordway DE, Vaergervik K: Birth prevalence, mutation rate, sex ratio, parent's age and ethnicity in Apert syndrome. Am J. Med. Genet 1997, 72: 394-98

10. Cohen, M. M Jr.; Kreiborg, S.; Lammer, E.J.; Cordero, J.F.; Mastroiacovo, P.; Erickson, J.D.; Roeper, P.; Martinez-Frias, M.L.: Birth Prevalence study of the Apert syndrome. Am. J. Med. Genet. 42: 655659, 1992.

11. Sedano, H; Sauk, J; Gorlin, R.J.: Oral Manifestations of Inherited Disorders.Editado por Butterworth Group. 1977: 88-89.

12. Cohen, M. M., Jr.; Kreiborg, S. : The central nervous system in the Apert syndrome. Am. J. Med. Genet. 35: 36-45, 1990.

13. Kaloust, S; Ishii, K; Vargervik, K.: Dental development in Apert syndrome. Cleft Palate Craniofac J, 34(2): 117-21 Mar 1997.

14. Lajeune E, Cameron R, El Ghouzzi V. Clinical variability in patients with Apert syndrome. J. Neurosurg 1999, 90:443-47

15. Kaplan, L.: Clinical Assessment and Multispecialty Management of Apert Syndrome. North Am.Clinics in Plastic Surgery 18 (2) 1991.

16. Cohen MM, Kreiborg S. Cutaneous manifestations of Apert syndrome. Am J Med Genet 1995;58:9496.

17. Ferreira JC, Carter SM, Bernstein PS, Jabs EW, Glickstein JS, Marion RW, et al. Second trimester molecular prenatal diagnosis of sporadic Apert syndrome following suspicions ultrasound findings. Ultrasound Obstet Gynecol 1999;14:426-430.

18. Boog G, Le Vaillant C, Winer N, David A, Quere MP, Nomballais MF. Contributions of tridimensional sonography and magnetic resonance imaging to prenatal diagnosis of Apert syndrome at mid trimester. Fetal Diagn Ther 1999;14:20-23.

19. Losa ME, Becerro de Bengoa R. Técnica de Padding: Tipos y Técnica de Aplicación según la Patología del Pie. Madrid: C.E.R.S.A, 2005.

20. Michaud TC. Foot Orthoses \& Other Forms Conservative Foot Care. Hardcover: Williams \& Wilkins, 1993.

21. Losa M.E, Becerro de Bengoa R. Criterios Americanos de Patología Podológica. En Levy AE, Cortes JM. Ortopodología y Aparato Locomotor. Barcelona: Masson S.A, 2003.

22. Dorca A, Dorca M. R, Caro R. La ortopodología en el síndrome de Apert. El Peu. 2003; 23(3):134139. 